\title{
COMPARISON OF BLOOD PRESSURE IN DEAF SECONDARY SCHOOL CHILDREN AND THEIR HEARING COUNTERPARTS: ASSOCIATION BETWEEN NOISE AND BLOOD PRESSURE
}

\author{
*OGB Nwaorgu and **OS Arulogun \\ *Department of Otorhinolaryngology, College of Medicine, University of Ibadan. \\ ** Department of Health Promotion and Education, College of Medicine, University of Ibadan \\ Corresponding Author \\ OS Arulogun
}

\begin{abstract}
Background and Objective: High blood pressure has been known to be one of the problems that could develop as a result of exposure to noise. Consequently, those who are hearing impaired are thought to be immune to this. This study assessed the relationship between noise exposure and blood pressure.

Methodology: This is a comparative prospective study involving participants (consisting of the hearing and the hearing impaired) drawn from a school environment that is situated close to a major highway and railway and evaluating the impact of noise on their blood pressure.

Results: The study population consisted of 299 secondary school students. The noise sensitive group comprised 220 participants with normal hearing while the noise-insensitive group comprised 79 hearing impaired from the same school. More participants 6 (85.7\%) from the noise insensitive group were found to have significantly higher blood pressure than their hearing counterparts 1 (14.3\%). In addition, majority of the participants (63.1\%) irrespective of their level of noise sensitivity were underweight.

Conclusion: This study finds noise exposure alone not sufficient to bring about an increase in blood pressure of the studied population. This not withstanding we advocate for policy measures aimed at controlling the source of environmental noise around educational institution which will aid in reducing the adverse effects of noise on the school children.
\end{abstract}

KEYWORDS: Blood pressure, Hearing impairment, Body Mass Index, School Pupils.

\section{INTRODUCTION}

The world of the child is becoming noisier and noisier. Compared to the mid-fifties environmental noise levels (sources such as road traffic, aircraft) increased substantially, causing higher noise levels during the day and night time, at home, at school and during out-and indoor leisure time activities. Also, children spend increasingly more time in with other children in situations such as in day care institutions and kindergartens with high noise levels due to a combination of loud voices, loud toys and bad acoustics (Eddie 2001). In Nigeria, most children are observed to spend their time on the streets hawking goods with exposure to blaring car horns at very busy roads and record shops in a bid to augment family income. In an unknown percentage of households, nowadays television or audio equipment is turned on for the whole day thus creating a perpetual noisy environment for the child. Consequently children are a high - risk group vulnerable to the effects of chronic noise exposure (Haines et al 2001a).

While noise usually would not kill us, it can certainly make our lives miserable. Exposure to noise affect human conditions in many serious ways namely permanent hearing loss, permanent tinnitus, stress, increase in blood pressure, disturbance in rest and sleep, sleep deprivation, fatigue, absenteeism, communication difficulties and affected learning and education (EPA Victoria 2003, Waters 1998). When considering the effects of noise on human health and quality of life, the intensity of the sound in question, its duration and the time and place at which it is heard had to be taken into consideration. Researches have revealed that low level chronic noise pollution resulting from everyday local traffic can have serious health implications for children increasing levels of stress hormones and raising blood pressure and heart rate (EPA Victoria 2003, Eddie News, 2001, Hygge 2000, Stansfeld 2000).

Because noise often does not produce visible effects, and because there is usually not a distinct cause-and -effect ("dose response" in medical terms) relationship between a single noise event and a clear adverse health effect, some people believe noise does not pose a serious risk to human health. But the evidence from a number of recent studies especially on children provides ample proof that noise harms human health and decreases quality of life (Haines et al 2001a,b,c, Griffith 2003). Noise-induced somatic effect such as blood pressure and hormone levels can best be considered as environment. Studies have shown 
that chronic exposure to aircraft noise in elementary schoolchildren can raise blood pressure and stress levels and cause defects in reading ability and long-term memory. Other studies show that children exposed to noise from elevated trains and highways at school also perform worse on standardized reading tests than do students at the same school in quieter classrooms (Aftandilian, 1999). An older crosssectional study showed unambiguously that environmental (aircraft) noise exposure is associated with an increase in (rested) systolic and diastolic blood pressure (Haines et al 2001b).

There is paucity of research into somatic, psycho-physiological and behavioral effects of noise on teenagers. A lot of studies have been devoted to noise-induced hearing impairment. It is in this view that this study was carried out because the increase in childhood stress could have a knock-on effect later in life. Anything that increases blood pressure has negative implications for long-term health effects.

\section{METHODS \\ Subjects}

This is a comparative prospective study involving participants drawn from a school environment that is situated close to a major highway and railway, which are large sources of noise. The level of highway traffic on the Bodija - University of Ibadan road is heavy and the noise comes from horn hooting, the engine, exhaust, sirens and faulty equipment like defective mufflers. Added to this are the locomotive engines of trains. Consent was obtained from the authorities of the School while informed consent was obtained from the subjects. The study observed the Helsinki declaration.

The study population was 299 hearing and hearing impaired students of Methodist Grammar School Bodija, Ibadan who had finished their sessional examinations. Junior Secondary three students were excluded from the study because they were writing their Junior Secondary examination, which was a stressor and could bring about an error in blood pressure reading. Also excluded were the multiply handicapped hearing impaired (i.e. those who had cerebral palsy in addition to hearing impairment). Relevant data such as age, height, weight, blood pressure and pulse rate were collected. Blood pressure measurement though simple is prone to inaccuracies and incorrect readings that can easily lead to errors of diagnosis. To reduce this, the procedure was explained verbally to the hearing students and through sign language to the hearing impaired by one of the researchers who is skilled in sign language usage before the commencement. It was emphasized that it may be necessary to repeat the measurement several times. Where higher values were obtained at first reading, the procedure was repeated after familiarity. Conversation was discouraged and avoided during blood pressure and pulse measurement. The automated sphygmomanometer (Blood Pressure Monitor WS520 model) was used in blood pressure measurement. The respondents were seated with arm positioned in such a way that it will be at the level of the heart. The measurement was carried out by one of the researchers.

The weight of the respondents were taken using the Hanson weighing scale while the height measurement was done first by marking the different heights on the wall and the respondents were asked to removed their sandals, stand against the wall with their heels touching the wall and a ruler is used to place their height against the premarked heights.

\section{RESULTS}

A total of 299 students comprising 220 hearing and 79 hearing impaired were studied. Of these 135 (45.2\%) were males and 164 (54.8\%) females, with male: female ratio of $1: 1.2$. The class of the participants showed that about a third (30.1\%) was in Senior Secondary class 2, followed by the $26.1 \%$ in the Senior Secondary class 1 . The age of participants ranged from 9 years to 26 years with a mean age of 15.2 years (Table 1 )

\section{Weight, Height and Body Mass Index (BMI) of participants}

The weights of participants ranged from $21 \mathrm{~kg}$ to $71 \mathrm{~kg}$ with a mean weight of $46.1 \mathrm{~kg}$. The heights of participants were measured and it ranged from 1.2 meters to 2.1 meters. The mean height is 1.5 meters with $67.4 \%$ of participants falling in the 1.5 meters -1.7 meters height group (Table 1 ).

The body mass index (BMI) of participants were calculated using the formula $\mathrm{BMI}=\mathrm{wt} / \mathrm{h}^{2}$. Using the Bray's classification, most of the participants (63.1\%) were underweight, 16(5.4\%) were overweight and 6(2.0\%) were obese. Only 89 (29.7\%) were within the normal weight limits (Table 2).

\section{Blood Pressure and Pulse Measurements}

Blood pressure measurements were taken for all the 299 students who participated in the study. The readings obtained were categorized using the World Health Organisation/ International Society of Hypertension classification of hypertension (Falase and Akinkugbe, 1999). Based on this classification, only 7 (2.3\%) participants had blood pressure readings that were higher than the normal value. Of these 7,6 (85.7\%) were hearing 
impaired. These differences were subjected to statistical analysis by comparing the systolic and diastolic blood pressure in the two groups and were found to be statistically significant $(\mathrm{p}<$ 0.05). When the values of height, weight and overweight, 1 (14.3\%) was obese, 1 (14.3\%) BMI of these 7 were looked at, 1 (14.3\%) was underweight while 4 (57.1\%) were within the normal limits (Table 3). The differences in pulse rate and $\mathrm{BMI}$ index were not significant. $(\mathrm{P}>0.05)$

Table 1. Demographic characteristics of subjects.

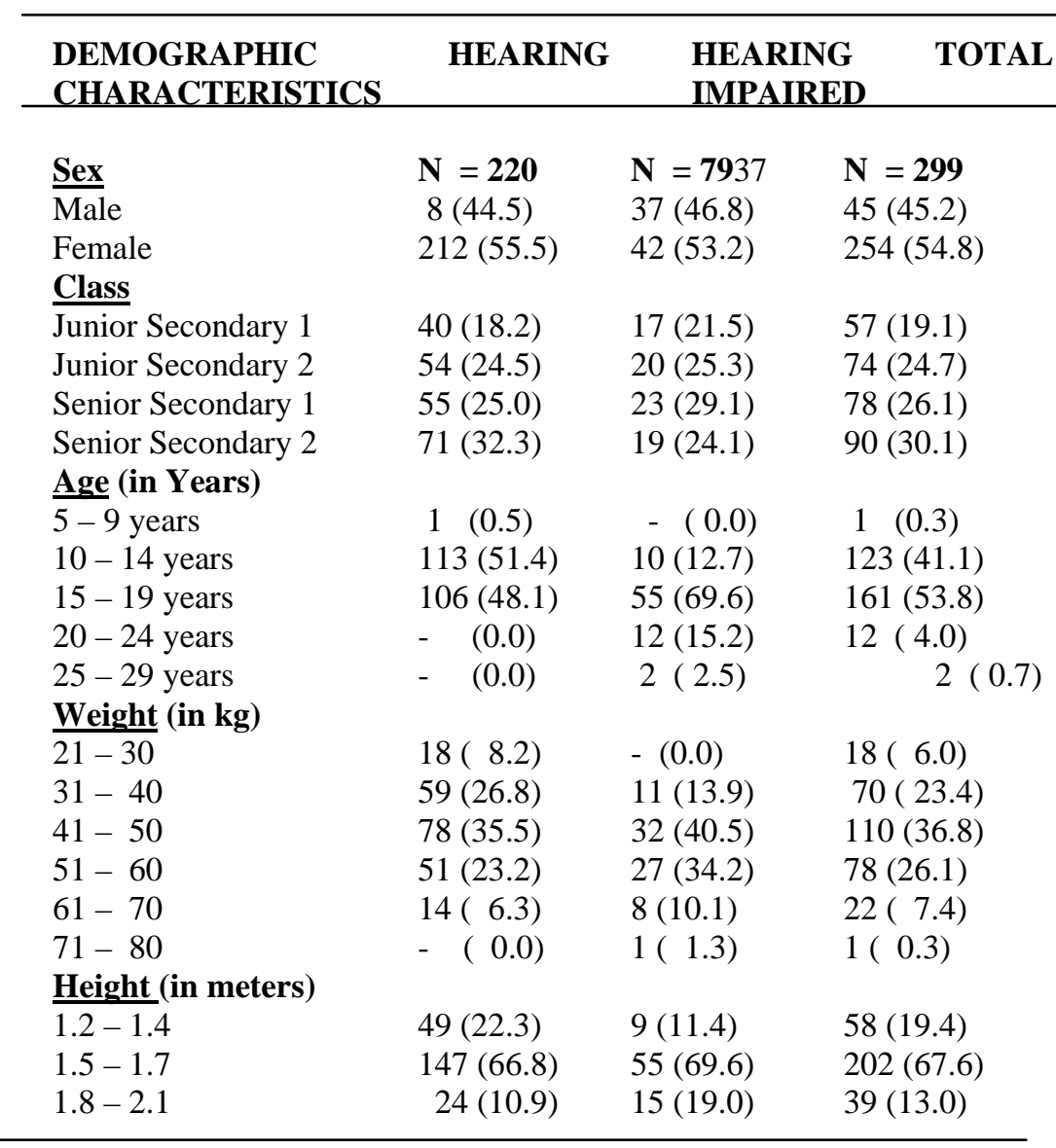

Table 2. Body mass index (BMI) of subjects.

\begin{tabular}{lccc}
\hline BODY MASS INDEX & $\begin{array}{c}\text { HEARING } \\
\text { IMPARIED }\end{array}$ & HEARING & TOTAL \\
\hline$<20$ underweight & $145(65.9)$ & $43(54.4)$ & $188(62.9)$ \\
$20-25$ normal & $60(27.3)$ & $29(36.7)$ & $89(29.7)$ \\
$>$ 25-30 overweight & $11(5.0)$ & $5(6.3)$ & $16(5.4)$ \\
$>30$ obese & $4(1.8)$ & $2(2.5)$ & $6(2.0)$ \\
\hline
\end{tabular}

Table 3. Comparision of height, weight and body mass index of 7 subjects with high blood pressure.

\begin{tabular}{lcccc}
\hline TYPE OF RESPONDENT & $\begin{array}{c}\text { HEIGHT } \\
\text { (M) }\end{array}$ & $\begin{array}{c}\text { WEIGHT } \\
\text { (KG) }\end{array}$ & $\begin{array}{c}\text { BODY MASS } \\
\text { INDEX }\end{array}$ & TOTAL \\
\hline Hearing & 1.5 & 60 & $27 \mathrm{OW}$ & $1(2.3)$ \\
Hearing Impaired & 1.7 & 58 & $20 \mathrm{NW}$ & \\
& 1.5 & 55 & $24 \mathrm{NW}$ & \\
• OW - Overweight & 1.2 & 46 & $32 \mathrm{OB}$ & $6(85.7)$ \\
$\bullet \quad$ NW - Normal & 1.5 & 50 & $22 \mathrm{NW}$ & \\
$\bullet \quad$ OB - Obese & 1.7 & 62 & $22 \mathrm{NW}$ & \\
$\bullet \quad$ UW - Underweight & 1.8 & 55 & $16 \mathrm{UW}$ & \\
\hline
\end{tabular}




\section{DISCUSSION}

The study showed more hearing students are in school attendance than their hearing impaired counterparts. Also the hearing impaired students were found to be older in age than their hearing counterparts. This could be attributed to their disability which makes them start school later than their hearing counterparts and many drop out at primary school level, a trend that has improved over the years.

More hearing impaired were found to have significantly higher systolic and diastolic blood pressure. This is at variance with the study of Wu, Chiang, Huang and Chang (1993) who found their hearing impaired subjects to have significantly lower blood pressure than their normal hearing counterparts. Our finding could be as a result of the inherent anxieties of the hearing impaired. Every teenager and young adult manifest a desire to please, wish to be liked but while outwardly calm, the hearing impaired's internal stance is that of suppressed anger, tension, suspicion and hostility by virtue of their disability which hinge on communication.

Also, there was evidence in the study that physical activity can reduce blood pressure. This was found in a participant whose weight was $65 \mathrm{~kg}$ and height $1.4 \mathrm{~m}$ but had very low blood pressure of $96 / 80 \mathrm{~mm} \mathrm{H}_{\mathrm{g}}$. He had history of sporting activities. This was in line with findings of Korner (1988) who found circum-stantial evidence from epidemiological studies that physical exercise per se can reduce arterial pressure has been confirmed in controlled trials. The findings of this study have raised the need for further research into other effects of the environmental noise on academic performance as well as nutrition education for the subjects and their cohorts. From this study, it became obvious that the children have to be monitored and followed-up to prevent or maintain pressure levels as it is known that children who gain weight more rapidly especially in their teens show generally the most rapid age-related rise in blood pressure and are likely to have high blood pressures as adults (Waters 1998, Ramsay 1987).

\section{CONCLUSION}

The study set out to assess the relationship between noise and blood pressure by comparing the blood pressure level of hearing impaired students and their hearing counterparts. The study found that more of the noise-insensitive group had elevated blood pressure than their hearing counterparts. Other findings like majority of participants being underweight with its inherent implications were also noted. As a result, more studies need to be done in this field.

In conclusion there is the need to adopt simple "good neighbour" behaviours for the benefit of children and society at large. The study is also advocating for policy measures to control the source of environmental noise around institution of learning thereby reducing the adverse effects of noise on the school children.

\section{REFERENCES}

- Aftandilian D. (1999) Noise Pollution. Conscious Choice, June.

- Bray GA. (1989) Classification and evaluation of the obesities. Medical Clinics of North America, 73: 111-184.

- Eddie Newsroom (2001) Chronic noise pollution harms health and well being of children. Eddie Weekly Summaries 25 ${ }^{\text {th }}$ May. Feversham House Group Ltd.

- EPA VICTORIA (2003) Environment - Noise for Students, Saturday 31 $31^{\text {st }}$ May.

- Falase AO and Akinkugbe OO. (1999) A Compendium of Clinical Medicine_Spectrum Books, Ibadan, Nigeria.

- Griffith RW. (2003) Noise - Induced Hearing Loss. National Institute on Deafness and Other Communication Disorders [NIDCD] August, 7.

- Hygge S. (2000) Effects of Aircraft Noise on Children's Cognition and Long term Memory. FICAN Symposium, February 16, San Diego, California.

- Haines M, Stansfeld S, Job R, Berglund B. and Head J. (2001a) A follow - up study of effects of chronic noise exposure on child stress responses and cognition. International Journal of Epidemiology, 30: 839 - 845.

- Haines M, Stansfeld S, Job R, Berglund B. and Head J. (2001b) Chronic aircraft noise exposure, stress responses, mental health and cognitive performance in school children. Psychological Medicine, 31: 265- 277.

- Haines M, Stansfeld S, Brentnall S, Head J, Berry B, Jiggins M. and Hygge S. (2001c) The West London Schools Study: effects of aircraft chronic noise exposure on child health. Psychological Medicine, 31: 1385-1396.

- Korner PI. (1988) Integrative neurohumoral control of the circulation. Australian Soc Exp. Biol. Proc. 1: 151.

- Ramsay LE. (1987) Dietary aspects of prevention and treatment of hypertensives. Curr. Opin. Cardiol., 2: 758.

- Stansfeld, S., Haines, M. And Brown, B. (2000) Noise and Health in the Urban Environment. Reviews on Environment Health, 15: 43-82.

- Waters M. (1998) Airplane noise may affect children's mental health. American Psychological Association, 29(5), May.

- Wu TN, Chiang HC, Huang JT and Chang PY. (1993) Comparison of blood pressure in deaf mute children and children with normal hearing: association between noise and blood pressure. International Archives of Occupational and Environmental Health, 65(2): 119-123. 